\title{
Brain Hypometabolism of Glucose in Anorexia Nervosa: Normalization after Weight Gain
}

\author{
Delvenne Véronique, Goldman Serge, De Maertelaer Viviane, SimonYves, Luxen André, Lotstra \\ Françoise
}

Department of Psychiatry, (VD, FL, YS), PET/Biomedical Cyclotron Unit (SG, AL), Hôpital Erasme and IRIBHN Statistical Unit (VD), Université Libre de Bruxelles, Brussels, Belgium.

\begin{abstract}
Using positron emission tomography and (18-F)-fluorodeoxyglucose, we studied cerebral glucose metabolism in 10 anorectic girls within their underweight state and after weight gain. Ten age- and sexmatched healthy volunteers were used as controls. Both groups were scanned during rest, eyes closed and with low ambient noise. In absolute values, the underweight anorectic patients, when compared to control subjects, showed a global $(p=0.002)$ and regional $(p \leq 0.001)$ hypometabolism of glucose which normalized with weight gain. In relative values, no global difference could be assessed between underweight anorectic patients and controls but a trend can, nevertheless, be observed toward parietal and superior frontal cortex hypometabolism associated with a relative hypermetabolism in the caudate nuclei and in the inferior frontal cortex. After weight gain, all regions normalized for absolute and relative values, although a trend appears toward relative parietal hypometabolism and inferior frontal cortex hypermetabolism in weight gain anorectic patients.

Absolute brain glucose hypometabolism might result from neuroendocrinological or morphological aspects of anorexia nervosa or might be the expression of altered neurotransmission following deficient nutritional state. As some differences exists in relative values in underweight patients and tend to persist in weight gain states, this could support a potential abnormal cerebral functioning, a different reaction to starvation within several regions of the brain or different restoration rates according to the region.
\end{abstract}

Key Words: Anorexia nervosa, PET scan, FDG, cerebral metabolism

\section{Introduction}

Anorexia nervosa is a complex syndrome where the most prominent symptom is weight loss. Different clinical characteristics, however, such as disturbances in the perception of body shape, high levels of motor restlessness and hyperactivity are associated with strategies to induce weight loss such as restricting food, vomiting, purging, or abuse of diuretics or appetite suppressants.

A number of metabolic and endocrine abnormalities, mainly at the hypothalamic level, have been described in anorexia nervosa (Wakeling 1985). Much evidence suggests that most of these changes are secondary to low weight and caloric deprivation, as they revert to normal with weight restoration and eating a normal diet.

Concerning central nervous system neurotransmitters, a significant reduction of cerebrospinal fluid (CSF), metabolites of serotonine and dopamine (Kaye et al 1984), or opiate-related peptides (Kaye et al 1987) have been observed in anorexia nervosa. These levels do normalize with weight restoration, however, long-term weight-restored anorectics had elevated concentrations of CSF 5-HIAA (Kaye et al 1991) and a reduction of CSF norepinephrin levels (Kaye et al 1984). These findings might be correlated to some clinical characteristics such as altered mood, anxiety, or obsessional thinking observed in anorexia nervosa. It has also been postulated that these neurochemical changes precede the onset of abnormal eating behavior and are the consequence of a primary stress reaction (Donohoe 1984).

A possible genetic vulnerability to environmental stress has been suggested following family and twin studies (Holland et al 1988). What is not known is the nature and the importance of this vulnerability in the etiology and in the development of anorexia nervosa.

Structural brain changes in anorexia nervosa, characterized by a reversible decrease of brain volume, were described in a number of CT scan studies. These ventricular and sulcal enlargements seem related to malnourish-ment and are partly reversible after weight restoration (Artmann et al 1985; Krieg et al 1988), however no satisfactory explanation has been proposed for these morphological brain alterations. 
Supporting the hypothesis of a central nervous system disorder, neuropsychological evaluation of patients with anorexia nervosa showed impaired cognitive performance which appeared to be a sign of poor prognosis at follow-up (Fox 1981; Hamsher et al 1981; Small et al 1983).

Brain glucose metabolism evaluated by Positron Emission Tomography (PET) is a dynamic method to evaluate cerebral functioning. In low-weight anorectic patients we have found an absolute global and regional hypometabo-lism of glucose which is most important in frontal and parietal cortices (Delvenne et al 1995). In order to evaluate the reversibility of this cerebral dysfunction, we evaluated glucose cerebral metabolic rates (CMRglu) in 10 anorectic patients in their underweight state and after weight gain. Ten sex and age-matched subjects were used as controls.

\section{Methods}

\section{Subjects}

Ten females meeting DSM-IV criteria for anorexia nervosa (American Psychiatric Association 1994), who were hospitalized in the Department of Psychiatry at Erasme Hospital, Free University of Brussels, consented to participate in this PET study. The patients were studied first in their underweight state and then, after weight-gain. Five of these patients have also participated in our previous study (Delvenne et al 1995). Their mean age ( \pm SD) was $20.0 \pm 3.9$ years (range 14-29 years). They all underwent a structural interview with the Schedule for Affective Disorders and Schizophrenia (SADS, Spitzer et al 1978) for patients above 16 years and the Schedule for Affective Disorders and Schizophrenia for School Age Children (K-SADS, Chambers et al 1985) for patients younger than 16. Six patients were restrictive anorectics while the remaining four displayed episodes of binge-eating. Major depressive disorder was present in two patients while the others were free of any comorbidity. All patients were free of psychotropic medication for at least 10 days and none had ever received neuroleptics or electroconvulsive therapy. Apart from emaciation and secondary amenorrhea, underweight anorectic patients had no significant abnormalities on physical and neurological examination including electroencephalogram. Laboratory screening tests were within normal range including serum protein level. Concerning thyroid functioning, three patients had a low T3. For the underweight anorectic patients, PET studies were performed following the first week of voluntary hospitalization. At that time, patients ate regular hospital meals with caloric intake around $1500 \_1800$ $\mathrm{kcal}$ and they were controlled for binge-eating and purging. Before PET examination, patients fasted for two hours to allow stable plasma glucose levels during the PET procedure. At that time, starvation ketosis was excluded by means of serum glucose level which was in the normal range (70-100 mg/dl) or by a negative test for ketones in urine. The anorectic patients were re-examined after weight gain following a period of behavior inpatient therapy.

The Body Mass Index (BMI, Rolland-Cachera 1985, 1988), which is the weight over the squared height ratio, was used as measure of corpulence. Underweight anorectic girls were under $85 \%$ of normal weight (mean weight $\pm \mathrm{SD}$ in kilograms $=37.3 \pm 5.1$; mean height $\pm \mathrm{SD}$ in meters $=1.64 \pm 0.1$; mean $\mathrm{BMI} \pm \mathrm{SD}=13.7 \pm 1.7)$. At the time of the second PET examination, anorectic patients had an average weight gain of $20 \%$ (mean weight \pm SD in kilograms $=48.8 \pm 5.1$; same height; mean BMI \pm $\mathrm{SD}=18.1 \pm 1.7)$

Data was compared with those from ten healthy and age-matched females (mean age \pm SD of $23.8 \pm$ 4.8 years, ranging from 18-30 years). They were screened for a negative personal and family history of psychiatric illness and they had no medical problems. All of them had a normal corpulence (mean weight $\pm \mathrm{SD}$ in kilograms $=59.8 \pm 10.8$; mean height $\pm \mathrm{SD}$ in meters $=1.65 \pm 0.1$; mean $\mathrm{BMI} \pm \mathrm{SD}=$ $21.9 \pm 3.3)$.

Patients and controls displayed the same educational and socio-economic status. The patients, and when necessary, their parents gave informed consent to participate in this study. Use of PET with 18 FFDG for the study of mental disorders has been approved by the ethics committee of our hospital.

\section{Ratings}

Evaluation was completed on the day of the PET study by:

1. The Eating Attitude Test (Garner and Garfinkel 1979): mean score during the underweight state \pm SD of $56.6 \pm 22.8$.

2. The 24-item Hamilton Depression Rating Scale (Hamilton 1960): mean score during the underweight state \pm SD of $19.4 \pm 11.9$ (range 4-40).

3. The Edinburgh Handedness Inventory (Oldfield 1971): one anorectic patient and one control girl were left-handed, the remaining ones were right-handed. 
Immediately after the PET procedure, patients and control subjects filled in the 20-item Spielberger State Anxiety Questionnaire (1968):

- Mean scale I and II scores for the underweight anorectics \pm SD: $47.1 \pm 10.5$ and $58.1 \pm 12.3$.

— Mean scale I and II scores for the weight-restored anorectics \pm SD: $42.2 \pm 7.9$ and $52.7 \pm 7.4$.

(o) Mean scale I and II scores for control subjects \pm SD: $28.5 \pm 4.0$ and $35.6 \pm 4.8$.

\section{Experimental Procedure}

Intravenous bolus of three to five $\mathrm{mCi}$ of FDG was administered to each subject resting in a supine state with eyes closed and ears unplugged, in a quiet and dimly lighted room. Fifteen seconds to 50 minutes after intravenous injection, 21 serial blood samples were centrifuged and plasma was counted in a gamma counter. Glucose level was determined in four blood samples at 0, 10, 20, and 40 minutes and the mean value was used to calculate cerebral metabolic rates of glucose (CMRglu).

The activity of the tracer in the brain was measured with an 8-ring CTI-Siemens tomograph (933-0812. Knoxville, TN) providing fifteen $7 \mathrm{~mm}$-thick adjacent slices through the entire brain. FDG was automatically synthesized using the procedure described by Hamacher et al (1986).

After a 10-minute blank scan acquisition, the subjects were positioned in the PET camera so as to obtain slices parallel to the canthomeatal. Subject immobility was checked using crossed laser beams and lines drawn on the subject's face. Using a source filled with a ${ }^{18}$ F-fluoride solution, a 10 -minute transmission scan was performed. Forty minutes after the FDG injection, a 20-minute emission scan was started. Plasma and brain radioactivity were corrected for decay and PET images were corrected for attenuation using transmission scan data.

Glucose computation was performed using the CTI software base on the model of Sokoloff et al (1977) adapted by Phelps et al (1979). The value used for lumped constant was 0.42 . Values were expressed in $\mu \mathrm{mol} / 1 \theta \theta \mathrm{g} / \mathrm{min}$.

To evaluate regional cerebral glucose metabolic rates (rCMRglu), we delineated 47 irregular regions of interest (ROI), 20 bilateral, and four medial regions, on PET slices following a template base on the human brain stereotaxic atlas of Talairach (1988). All ROI were grouped in eight anatomical regions (Delvenne et al 1995). Thalamus, caudate nucleus, and putamen, appearing on several adjacent slices, were studied as a surface-weighted mean of CMRglu: sum of the mean values of glucose $\left(\mathrm{m}_{\mathrm{i}}\right)$ multiplied by the number of pixel $\left(\mathrm{p}_{\mathrm{i}}\right)$ and divided by the number of pixel $=\sum\left(\mathrm{m}_{\mathrm{i}} \mathrm{x} \mathrm{p}_{\mathrm{i}}\right) / \sum \mathrm{p}_{\mathrm{i}}$. If a structure was not clearly visualized at one of the predefined levels, the average was calculated for this patient on a reduced number of slices.

Global absolute cortical values of glucose $\left(\mathrm{ROI}_{\mathrm{G}}\right)$ were obtained by the mean cortical values which were obtained by the sum of the mean values of glucose $\left(\mathrm{m}_{\mathrm{i}}\right)$ multiplied by the number of pixel $\left(\mathrm{p}_{\mathrm{i}}\right)$ and divided by the number of pixel $=\sum\left(\mathrm{m}_{\mathrm{i}} \bullet \mathrm{p}_{\mathrm{i}}\right) / \sum \mathrm{p}_{\mathrm{i}}$. Left, right, and median cortical values of glucose ( $\mathrm{ROI}_{\mathrm{L}}, \mathrm{ROI}_{\mathrm{R}}, \mathrm{ROI}_{\mathrm{M}}$ ) were obtained similarly by the mean homolateral or median cortical values. Relative regional metabolic rates of glucose (rCMR-glu rel) were calculated as absolute ROI values divided by these cortical values of glucose $\left(\mathrm{ROI}_{\mathrm{L}}, \mathrm{ROI}_{\mathrm{R}}, \mathrm{ROI}_{\mathrm{M}}\right)$ respectively for left, right, and median ROI.

\section{Statistical Analysis}

In a first analysis $\mathrm{ROI}_{\mathrm{G}}, \mathrm{ROI}_{\mathrm{L}}, \mathrm{ROI}_{\mathrm{R}}$, and $\mathrm{ROI} \mathrm{M}$ rCMRglu were used as estimates of global, left and right, and median hemispheric glucose metabolism. They were compared between underweight anorectics and controls and between weight-gained anorectics and controls with the use of a Student $t$ test.

Eight neuroanatomic regions were analyzed with multivariate analyses of variance (MANOVASPSS, 1988): (1) superior frontal cortex, (2) lateral inferior frontal cortex, (3) median inferior frontal cortex, (4) parietal cortex, (5) temporal cortex, (6) thalamus, (7) caudate nuclei, (8) putamen. The MANOVA included one between subjects factor at two levels (underweight anorectic patients, controls) and one repeated measures factor at eight levels (the eight zones). They were performed on the mean left/right values of glucose. All main effects and interactions were introduced into the model. Contrasts of the "difference" type were performed among the eight zones. 
Table 1. Absolute Metabolic Rates for Glucose Respectively in the Global Cortex Then in Left, Right and Median Cortices ( $\mu$ Moles of Glucose/Min/100 g of Brain \pm SD)

$\begin{array}{lll}\begin{array}{l}\text { Normal } \\ \text { controls }\end{array} & \begin{array}{l}\text { UW anorectic } \\ \text { patients }^{\mathrm{a}}\end{array} & \begin{array}{l}\text { W-G } \\ \text { anorectic } \\ \text { patients }^{\mathrm{b}}\end{array} \\ 29.64 \pm 1.93 & 23.23 \pm 4.93 & 28.28 \pm 2.96 \\ & & \\ 29.93 \pm 1.68 & 23.40 \pm 5.06 & 28.46 \pm 2.98 \\ 29.73 \pm 2.06 & 23.11 \pm 5.01 & 28.24 \pm 3.13 \\ 28.94 \pm 1.81 & 22.78 \pm 4.42 & 27.75 \pm 2.65 \\ & & \\ & \\ & \end{array}$

The mean values of each zone were compared between underweight anorectic patients and controls with the Student's $t$ test. This procedure was applied on absolute rCMRGlu and then on relative values. Underweight and weight-gained anorectic patients were compared for global, left, and right hemispheric metabolism of glucose, as well as for absolute and relative rCMRglu of the eight zones, with Student's $t$ tests for paired samples.

Scores on the BMI and scores of anxiety on the Spielberger scale were correlated, within each group (underweight and weight-gained anorectic patients and controls), with absolute and relative CMRglu values using the Spearman rank correlation coefficient (Siegel 1956). Similar correlations were performed for the Hamilton rating scale for depression but in the underweight anorectic group only.

\section{Results}

\section{Clinical Data}

Age of patients and controls was not statistically different ( $t$ test, $p=0.07)$. Underweight and weightgained anorectic patients appeared to be significantly more anxious $(p=0.001)$ than controls. At time of the second PET-scan, weight-gained anorectics still remained anxious and their scores were not significantly different than at the time of the first examination. Weight-gained patients still presented significant lower weights than control subjects ( $t$ test for the BMI, $p=0.004$ ).

\section{Absolute Glucose Metabolic Rates}

GLOBAL CORTICAL METABOLISM. Absolute CMRglu in the global cortex $\left(\mathrm{ROI}_{\mathrm{G}}\right)$ as well as in $\mathrm{ROI}_{\mathrm{L}}$, $\mathrm{ROI}_{\mathrm{R}}$, and $\mathrm{ROI}_{\mathrm{M}}$ (Table 1) was significantly different between underweight anorectic patients and controls $(p \leq 0.003)$.

Table 2. Mean Left-Right Absolute Regional Cerebral Metabolic Rates for Glucose ( $\mu$ Moles of Glucose/Min/100 g of Brain $\pm S D$ )

Normal controls UW anorectic patients ${ }^{\mathrm{a}} \mathrm{W}-\mathrm{G}$ anorectic patients ${ }^{\mathrm{b}}$

\begin{tabular}{|c|c|c|c|}
\hline Superior-frontal cortex & $32.90 \pm 2.71$ & $24.91 \pm 5.67^{\mathrm{c}}$ & $30.34 \pm 3.32$ \\
\hline Inferior-frontal cortex lateral & $28.55 \pm 2.03$ & $23.21 \pm 4.87^{\mathrm{d}}$ & $28.23 \pm 3.13$ \\
\hline Inferior-frontal cortex median & $28.13 \pm 1.39$ & $22.47 \pm 4.49^{\mathrm{d}}$ & $27.25 \pm 2.50$ \\
\hline Temporal cortex & $23.81 \pm 1.68$ & $19.42 \pm 4.06^{\mathrm{d}}$ & $23.03 \pm 2.59$ \\
\hline Parietal cortex & $32.23 \pm 2.50$ & $23.32 \pm 5.77^{\mathrm{c}}$ & $29.41 \pm 3.39^{\mathrm{e}}$ \\
\hline Thalamus & $30.09 \pm 2.89$ & $24.71 \pm 4.61^{\mathrm{d}}$ & $29.09 \pm 3.46$ \\
\hline Putamen & $33.43 \pm 2.90$ & $27.10 \pm 4.54^{\mathrm{d}}$ & $31.99 \pm 3.65$ \\
\hline Caudate & $30.56 \pm 2.94$ & $25.08 \pm 4.11^{\mathrm{d}}$ & $28.93 \pm 3.78$ \\
\hline
\end{tabular}


0.9; region difference: $p<0.001$; the interaction was not significant.

$c_{p}=0.001$

$d_{p}<0.001$ (within region group differences).

$e_{p}<0.05$ (non-significant with Bonferroni's correction) (within region group differences).

CMRglu of weight-gained anorectic patients was not statistically different from normal controls in the same ROI.

CORTICAL AND SUBCORTICAL REGIONS. Considering the eight mean right/left regions, the absolute rCMRglu was found to differ significantly between underweight anorectic patients and controls (group difference, $p=0.001$; region difference, $p<0.001$ ). Contrast analysis considering the differences in the mean values of cortical and subcortical regions (Table 2) showed a significant hypometabolism of glucose $(p<0.01)$ in each of the eight regions being mostly significant $(p=0.001)$ in the superior frontal and parietal cortices of underweight anorectics.

Comparison of absolute rCMRglu between weight-gained anorectics and controls in the eight mean right/left regions showed no significant group difference (group difference, $p=0.9$; region difference, $p$ $<0.001)$. Nevertheless, when looking at the difference between weight-gained patients and controls within each of the eight regions, we observed a lower metabolism which persisted in the parietal cortex $(p<0.05)$ at the time of the second evaluation.

\section{Relative Glucose Metabolic Rates}

Only a slight difference between underweight anorectic patients and controls was found after analysis of the relative rCMRGlu considering globally the eight mean right/left regions (group difference, $p=$ 0.057; region difference, $p<0.001)$.

Table 3. Mean Left-Right Relative Regional Cerebral Metabolic Rates for Glucose Normal controls UW anorectic patients ${ }^{\mathrm{a}} \mathrm{W}-\mathrm{G}$ anorectic patients $\mathrm{b}$

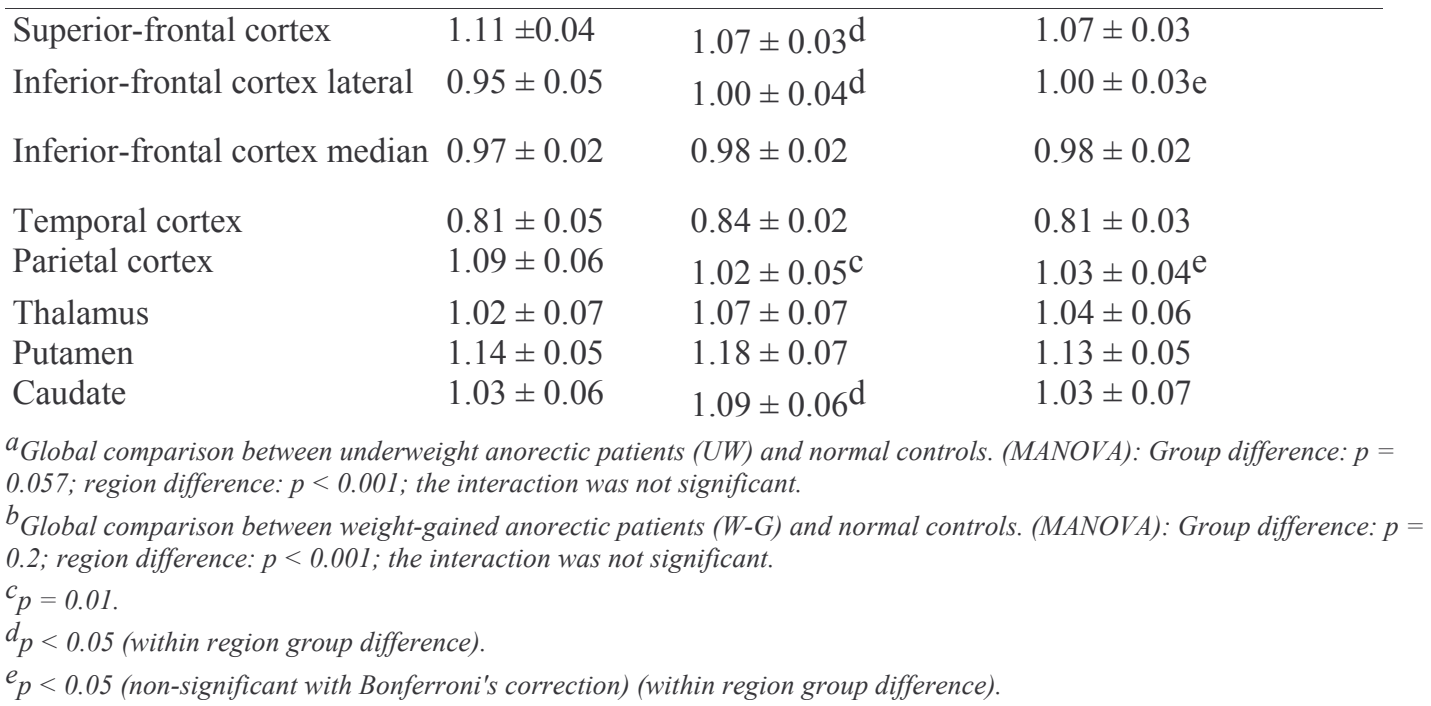

Contrasts analysis of the "difference" type was performed on the mean relative values of cortical and subcortical regions. It showed a significant hypometabolism in the parietal cortex $(p<0.01)$, in the frontal superior cortex $(p<0.05)$ and a relative hypermetabolism of the caudate nuclei and the inferior frontal cortex $(p<0.05)$.

When the eight mean right/left regions were compared between weight-gained anorectics and controls, no significant difference appeared (group difference, $p=0.2$; region difference, $p<0.001$ ). Contrasts analysis, nevertheless, showed a relative parietal hypometabolism $(p<0.02)$ and a relative inferior frontal hypermetabolism (Table 3).

\section{Correlations}

In the group of underweight anorectics, as well as in the weight-gained or control group, no correlation could be found between absolute rCMRGlu and BMI in each regions. Similarly, no significant 
correlation was noted between anxiety scores and absolute rCMRGlu (eight regions) within groups (patients and controls). No correlation was found in the underweight anorectic group between the Hamilton depression score and rCMRGlu.

\section{Comment}

This study confirms that underweight anorectic patients have global and regional absolute glucose cerebral hypo-metabolism especially important in the frontal and parietal cortices (Delvenne et al 1995). In relative values, while no global difference was observed between underweight anorectic patients and controls, comparisons within regions, nevertheless showed, a hypometabolism in the parietal and superior frontal cortices associated with a relative hypermetabolism in the caudate nuclei and in the inferior frontal cortex. After weight gain, following cognitive therapy and hospitalization, the absolute hypometabolism increased in all regions while the relative metabolism of glucose tended to remain abnormal in the parietal and inferior frontal cortices.

Low body weight or prolonged starvation state can be proposed to explain the absolute brain glucose hypome-tabolism as normalization was observed after weight gain, however, no correlation was observed between rCMRGlu and BMI within groups (underweight, weight-gained anorectics, controls). It has been suggested that acido-ketosis and high plasma levels of ketone bodies could explain hypometabolism of glucose selectively at the cortical level (Hawkins et al 1979; Herholz et al 1987) although the pathophysiological mechanism of this hypometabolism is unknown. At the time of the first PET, our patients were in a stable metabolic state controlled by the absence of ketone bodies in urine and constant normal plasma glucose levels, however, chronic effect of acido-ketosis on the brain following chronic starvation periods cannot be totally excluded. At the time of reevaluation, patients received stabilized caloric intake but for most of them, they were still gaining weight. So, we can not exclude that this might contribute to the persistent abnormalities.

Alterations in function related to glucose utilization are a result of changes occurring predominantly in nerve terminals rather than cell bodies (Roland 1993). Some central neurotransmitters systems have proved to be altered in anorectic patients with significant reductions of cerebrospinal fluid (CSF) 5hydroxyindole-acetic acid, norepinephrine and MHPG or homovanillic acid levels in the underweight anorectics (Fava et al 1989). These levels normalized with weight restoration with elevated concentrations of CSF 5-HIAA in long-term weight restored anorectics (Kaye et al 1991). Abnormalities of these modulatory amine transmitter systems could contribute to the absolute global hypometabolism but not to the relative regional glucose hypometabolism. Indeed, serotoninergic and noradrenergic fibers distribute diffusely in all cortical regions while dopaminergic fibers distribute only in certain cortical regions like the prefrontal cortex, the cingu-late cortex, and the archicortex. In addition, it is important to note that, besides this cerebral glucose hypometabolism, anorectic patients were also characterized by hyperactivity and they showed no global cerebral dysfunctioning on cognitive evaluation.

Abnormal hypothalamic functioning, characterized by neuroendocrine dysfunctions such as amenorrhea, was observed in our group of underweight anorectics. As some hypothalamic areas project to the subcortical as well as to the cortical regions (Saper 1990), this may also be proposed to explain brain glucose hypometabolism, however, these neuroendocrine dysfunctions have frequently delayed recovery after weight gain and our weight-gained anorectic patients, who had a normalized rCMRglu, were still amenorrheic.

Correlations between brain glucose hypometabolism and CT morphological abnormalities in anorexia nervosa remains questionable. Enlargement of the external cerebrospinal fluid spaces observed in severely emaciated anorectic patients in CT scan studies are partly reversed with weight recovery. The significance of this CT changes are unclear but different pathogenic mechanisms have been proposed: an inhibition of brain protein biosynthesis (Artmann et al 1985), hypercortisolemia causing cerebral dehydration or low plasma level of triiodothyronine (Krieg et al 1988), or a neuronal brain damage in those cases which did not reverse with weight recovery (Martin 1958; Artmann et al 1985). In this study, CT-scans were not performed in our patients for practical reasons and to avoid multiplication of X-ray exams.

Clinical characteristics of the anorectic patients, such as restrictive or binge-eating or purging types, might be proposed to explain metabolic changes. These subtypes did not seem to account for statistical differences while comparisons of rCMRglu between subgroups of anorectic patients was not significant, however, the number of patients for comparisons was reduced. Different psychopathological disturbances such as depression or anxiety have been demonstrated to influence cerebral glucose metabolism in different ways. Only two of our underweight anorectic patients had an additional diagnosis of major depressive disorder which was in remission at the time of reevaluation. 
Cerebral glucose metabolism of these two depressed anorectics did not differ from that of nondepressed patients. In addition, no correlation was found between reduced rCMRGlu and the Hamilton score within the group of underweight anorectics. As our patients had higher anxiety scores than control subjects in their underweight as in their weight-restored states, anxiety does not seem to influence global and regional hypo-metabolism of glucose. In addition, these anxiety scores were not correlated with rCMRGlu within groups.

In relative values, a hypometabolism in the parietal and superior frontal cortices associated with a relative hypermetabolism in the caudate nuclei and in the inferior frontal cortex was observed and it tended to remain abnormal after weight gain particularly in the parietal and inferior frontal cortices. The relative hypermetabolism in the caudate nuclei which normalized after weight gain has also been observed by Herholz et al (1987). This was not observed in our previous study probably because of a different way of normalization. This relative hypermetabolism in the caudate nuclei and in the inferior frontal cortex questions relationships between anorexia nervosa and obsessive compulsive disorder. Indeed, obsessional features focused on eating patterns were common in anorexia nervosa (Rothenberg 1986; Holden 1990) and a relative hypermetabolism of the orbito frontal gyri, corresponding to our inferior frontal cortex, and of the head of caudate nuclei has also been described in obsessive-compulsive patients (Baxter et al 1987; Nordahl et al 1989). Persistence of these abnormalities after weight gain might be associated with the persistence of obsessions concerning food, weight, and body shape in weight-restored anorectic patients.

A trend towards the persistence of an absolute or relative glucose parietal hypometabolism is observed in weight-gained anorectics. It might be related to weight while not all of our patients have recovered a normal weight at the time of reevaluation, however, no differences appeared for absolute or relative rCMRglu of patients with a BMI of or above 19 at the time of the second PET-scan. This specific parietal hypometabolism might support a possible primary cerebral dysfunction or a particular regional sensitivity to consequences of nutritional deficiencies with different restoration rates according to the region. Cognitive studies showing distortions of body image (Bowden et al 1989; Horne et al 1991) associated with the impairment of the awareness of emaciation and particular arithmetic low performances (Fox 1981; Ham-sher et al 1981; Small et al 1983) tend to support a parietal dysfunction in anorexia nervosa. In addition an elevated pain threshold was observed in eating disorder patients (Lautenbacher et al 1990) which was not the consequence of a peripheral polyneuropathy (Pauls et al 1991). This might correspond to the parietal hypometabolism observed in our study, however, separating cause-and-effect relationships is particularly difficult in such observations.

\section{Conclusion}

In the present study using PET and FDG, we found global and regional brain glucose hypometabolism in underweight patients with anorexia nervosa. Pathophysiological mechanism of this observation is unknown. It might derive from alterations in neurotransmitters system or from neuroendocrinological or morphological characteristics of anorexia nervosa possibly associated with low body weight or nutritional factors. Weight gain was followed by a normalization of this absolute hypometabolism while a trend towards a still relative parietal hypometabolism and inferior frontal hypermetabolism was observed. Further imaging studies comparing anorectic patients with underweight non-anorectic patients or other groups of psychiatric patients should clarify the relationship between glucose hypometabolism and persistent starvation states.

\section{References}

American Psychiatric Association (1994): Diagnostic and Statistical Manual of Mental Disorders, 4th ed, Washington DC: American Psychiatric Association.

Artmann H, Grau H, Adelmann M, Schleiffer R (1985): Reversible and non-reversible enlargement of cerebrospinal fluid spaces in anorexia nervosa. Neuroradiology 27:304-312.

Baxter LR, Phelps ME, Mazziotta JC, Guze BH, Swartz JM, Selin CE (1987): Local cerebral glucose metabolic rates in obsessive compulsive disorder. Arch Gen Psychiatry 44:211-218.

Bowden PK, Touyz SW, Rodriguez PJ, Hensley R, Beumont PJV (1989): Distorting patient or distorting instrument? Br J Psychiatry 155:196-201.

Chambers WJ, Puig-Antich J, Hirsch M, Paez P, Ambrosini PJ, Tabrizi MA, Davies M (1985): The assessment of affective disorders in children and adolescents by semistructured interview. Arch Gen Psychiatry 42:696-702.

Delvenne V, Lotstra F, Goldman S, Biver F, De Maertelaer V, Appelboom-Fondu J, Schoutens A, Bidaut LM, Luxen A, Mendlewicz J (1995): Brain hypometabolism of glucose in anorexia nervosa: A PET-scan study. Biol Psychiatry 37:161-169. 
Published in: Biological psychiatry (1996), vol. 40, iss. 8, pp. 761-768

Status: Postprint (Author's version)

Donohoe TP (1984): Stress-induced anorexia nervosa: implications for anorexia nervosa. Life Sci 34:203-218.

Fava M, Copeland PN, Schweiger U, Herzog DB (1989): Neurochemical abnormalities of anorexia nervosa and bulimia nervosa. Am J Psychiatry 146:963-971.

Fox CF (1981): Neuropsychological correlates of anorexia nervosa. Int J Psychiat Med 11:285-290.

Garner DM, Garfinkel PE (1979): The Eating Attitudes Test: An index of the symptoms of anorexia nervosa. Psychol Med 9:273-279.

Hamacher K, Coenen HH, Stocklen G (1986): Efficient ste-reospecific synthesis of no-carrier-added 2-18 F-fluoro-2-deoxy-Dglucose using aminopolyether supported nucleo-philic substitution. J Nucl Med 27:235-238.

Hamilton M (1960): A rating scale for depression. J Neurol Neurosurg Psychiatry 23:56-62.

Hamsher KS, Halmi KA, Benton AL (1981): Prediction of outcome of anorexia nervosa from neuropsychological status. Psychiatry Res 4:79-88.

Hawkins RA, Biebuyck JF (1979): Ketone bodies are selectively used by individual brain regions. Science 205:325-327.

Herholz K, Krieg JC, Emrich HM, Pawlik G, Beil C, Pirke KM, Pahl JJ, Wagner R, Wienhard K, Ploog D, Heiss W-D (1987): Regional cerebral glucose metabolism in anorexia nervosa measured by Positron Emission Tomography. Biol Psychiatry 22:4351 .

Holden NL (1990): Is anorexia nervosa an obsessive-compulsive disorder? Br J Psychiatry 157:1-5.

Holland AJ, Sicotte N, Treasure J (1988): Anorexia nervosa: evidence for a genetic basis. J Psychosom Res 32:561-571.

Home RL, Van Vactor JC, Emerson S (1991): Disturbed body image in patients with eating disorders. Am J Psychiatry 148:211215 .

Kaye WH, Berrettini WH, Gwirtsman HE, Chretien M, Gold PW, George DT, Jimerson DC, Ebert M (1987): Reduced cerebrospinal fluid levels of immuno-reactive propiomelano-cortin released peptides (including Beta-endorphin) in anorexia nervosa. Life Sci 41:2147-2155.

Kaye WH, Ebert MH, Raleigh M, Lake CR (1984): Abnormalities in CNS monoamine metabolism in anorexia nervosa. Arch Gen Psychiatry 41:350-355.

Kaye WH, Gwirtsman HE, George DT, Ebert MH (1991): Altered serotonin activity in anorexia nervosa after long-term weight restoration. Arch Gen Psychiatry 48:556-562.

Krieg JC, Pirke KM, Lauer C, Backmund H (1988): Endocrine, metabolic, and cranial computed tomographic findings in anorexia nervosa. Biol Psychiatry 23:377-387.

Lautenbacher S, Michaels AP, Strian F, Pirke KM, Krieg JC (1990): Pain perception in patients with eating disorders. Psychosom Med 52:673-682.

Martin F (1958): Pathologie des aspects neurologiques et psy-chiatriques de quelques manifestations carentielles avec troubles digestifs et neuro-endocriniens. Etude des alterations du systeme nerveux central dans deux cas d'anorexia survenue chez la jeune fille (dite anorexie mentale). Acta Neurol Belg 58:816-830.

Nordahl TE, Benkelfat C, Semple WE, Gross M, King AC, Cohen RM (1989): Cerebral glucose metabolic rates in obsessive compulsive disorder. Neuropsychopharmacology 2:23-28.

Oldfield RC (1971): The assessment and analysis of handedness: The Edinburgh Inventory. Neuropsychologia 9:97-113.

Pauls AM, Lautenbacher S, Strian F, Pirke KM, Krieg JC (1991): Assessment of somatosensory indicators of polyneuropathy in patients with eating disorders. Eur Arch Psychiatry Clin Neurosci 241:8-12.

Phelps ME, Huang SC, Hoffman EJ, Selin C, Sokoloff L, Kuhl DE (1979): Tomographic measurement of local cerebral glucose metabolic rate in humans with (F-18) 2-Fluoro-2-Deoxy-D-Glucose: validation of method. Ann Neurol 6:371-388.

Roland PE (1993): Cellular metabolism and blood flow. In Brain Activation, New-York: Wiley-Liss, pp 51-82.

Rolland-Cachera MF (1985): BMI Charts (I month-21 years). Graphique S.C.G. France, Institut National de la Santé et de la Recherche Medicale (INSERM).

Rolland-Cachera MF (1988): BMI Charts (1 month-85 years and over). France, Institut National de la Santé et de la Recherche Medicale (INSERM).

Rothenberg A (1986): Eating disorder as a modern obsessive-compulsive syndrome. Psychiatry 49:45-53.

Saper CB (1990): Hypothalamus. In Paxinas G The Human Nervous System, San Diego: Academic Press, pp 389-413.

Siegel S (1956): Non parametric statistics for the behavioral sciences. McGraw-Hill Kogakusha, LTD.

Small A, Madero J, Teagno L, Ebert M (1983): Intellect, perceptual characteristics, and weight gain in anorexia nervosa. J Clin 
Published in: Biological psychiatry (1996), vol. 40, iss. 8, pp. 761-768

Status: Postprint (Author's version)

Psychology 39:780-782.

Sokoloff L, Reivich M, Kennedy C (1977): The (14 c)-deoxy-glucose method for the measurement of local cerebral glucose utilization: Theory, procedure and normal values in the conscious and anesthetized albino rat. J Neurochem 28:897_-916.

Spielberger 20-item State Anxiety Questionnaire-Manual (1968): Palo Alto, California: Consulting Psychologists Press.

Spitzer RL, Endicott J (1978): Schedule for Affective Disorders and Schizophrenia. New York: New York State Psychiatric Institute. SPSS/PC+ V2.0 (1988): SPSS Inc; Chicago.

Talairach J, Tournoux P (1988): Co-planar stereotaxic atlas of the human brain-3-Dimensional Proportional System: An approach to cerebral imaging. Georg Thieme Verlag, New York: Thieme Medical Publishers, Inc.

Wakeling A (1985): Neurobiological aspects of feeding disorders. J Psychiat Res 19:191-201. 